\title{
Analyzing the Approach and Memory in the Developmental Process of Space Making Using 1:10 Scale Blocks
}

\author{
Samuel Tan*1 and Suguru Mori ${ }^{2}$ \\ ${ }^{1}$ Ph.D. Candidate, Faculty of Engineering, The University of Tokyo, Japan \\ ${ }^{2}$ Associate Professor, Graduate School of Engineering, Hokkaido University, Japan
}

\begin{abstract}
In this research, we attempt to highlight the differences between specialists and non-specialists in their overall approach and memory skills by comparing their 'micro acts' patterns, as they are constructing 'models' using 1:10 scale LEGO $^{\circledR}$ blocks. By focusing on 50 subjects (with and without architectural backgrounds), we observed and identified different patterns of combination and various transitional stages in their 'main micro acts' (attach act, detach act and pause act) during the construction of models under the proposed brief.

On the contrary to our first hypothesis, although subjects with architectural background applied more disrupted micro acts patterns during construction, it does not necessarily mean that they would replicate the required task as 'fluently' as other subjects with no architectural background. We noticed that a portion of the specialists who engaged the tasks more carefully initially also displayed some form of difficulties when attempting to replicate the models in the second trial. In contrast, there are a number of non-specialists who remembered better than their specialist counterparts, thus questioning the implications of 'subconscious playing' and 'conscious constructing'.
\end{abstract}

Keywords: micro acts patterns; micro slip; approach; space making; memory capacity

\section{Introduction}

The resultant product of 'architecture' is always an involvement in communication between different categories of specialists including the craftsmen, architects, engineers and the clients themselves. We know that all of them have their own unique perspectives, specific methods of perceiving, and approach to making spaces. Nevertheless, it is difficult to pin point these differences in an objective, yet analytical way. We know that in the case of specialists (see Table 5.) who have been trained to represent their conceptual 3 dimensional ideas into 2 dimensional drawings, their use of concepts such as sections, elevations and plans in scales (e.g. 1:100 scale) assists them in representing 3 dimensional architecture in 1:1 scale. Specialists from different fields have different approaches to translating 3 dimensional spaces perceived through the human brain into a physical reality. Most specialists who have learnt from their education were at one stage without these 'skills'. What comparisons can be made between specialists who have undergone an architectural education (for a certain number of years) and with non-specialists who have not?

\footnotetext{
*Contact Author: Samuel Tan, Ph.D. Candidate,

Namba Laboratory, Department of Architecture, Faculty of Engineering, The University of Tokyo 7-3-1 Hongo,

Bunkyo-ku, Tokyo 113-8656 Japan

Tel: +81-3-5841-7475 Fax: +81-3-5841-6186

E-mail:sam_in_aust@hotmail.com

(Received October 11, 2005 ; accepted January 26, 2006)
}

\section{Theoretical Background}

In this research, rather than focusing on internal workings of the brain which cognitive scientists have been doing, we have taken an ecological perspective using its analytical approach that aims to look at the entire picture by denying the internal representations created by the brain. Using ecological science as a theoretical formwork to analyze the participants' actions, we can highlight their differences.

J.J. Gibson (1986) developed the term 'ecological psychology' primarily for visual perception. He emphasized the importance of the larger interacting systems; stating that for one to fully understand a biological organism, one must also understand the organism as a member of a species, which is also a product of a long process of natural selection within a changing environment. According to Gibson, the environment not only serves as the surface that separates substance from the medium in which the animals live, it also affords the possibilities of terrain, shelters, water, etc. Not only is there information available for the perception of the environment, it also contains information which constitutes what they can afford. An affordance is holistic, and when we look at objects, it is their affordances and not their dimensions and properties that we perceive.

Moreover, Reed (1996) expanded the meaning of affordance by including the time dimension, suggesting that actions and awareness can be studied scientifically by proposing concepts such as the 'micro slip effect'. The 'micro slip effect' suggests that by utilizing the 
amount of deviation in our original and repeated actions, information regarding the manner which the brain processes can be concluded.

On a similar wavelength, a Russian scientist, Bernstein (1996) studied the actions of manual labourers and athletes as well as their brain structures which control those actions. From his studies, Bernstein presented an approach to problems of coordination and the control of movements. Using his techniques, an outsider can know the 'activities' of that person better than the person him/herself. He concluded that the noticeable patterns in movements are automated, which usually operates in the background of any actions. However, the newer patterns that are conscious related are yet to be fully understood.

In contrast to Gibson, Reed and Bernstein's works, Hawkins (2004) presented a new unified theory of the functions of cerebral cortex in perception, cognition in perception, cognition, action and also intelligence. $\mathrm{He}$ argued that the key to the brain and intelligence is the ability to make predictions about the world by seeing in patterns. He also argued that our memory's prediction system is implemented by the brain's cortex, functioning as the basis of human intelligence. Hawkins suggested that the brain's processing ability uses this particular method, arguing that in order for the computer to have intelligence like our human brains, we have to teach the computer to see, find and use patterns.

\section{Research Purpose}

Architects and designers are regarded as specialists in translating the clients' ideas from various degrees into actual physical built-form. Nevertheless, the process of making drawings often strains the clientarchitect relationship because each party has different ways of seeing and making space. Non-specialists (clients) do not possess the physical, technical and dimensional concept of space because they are not educated to make drawings whereas specialists (architects) are conditioned to transform 3 dimensional spaces into 2 dimensional drawings. As a result of such 'skills' differences, one can also reasonably suggest that they indeed perceive space differently. In many cases, some architects minimize their communication with clients, regarding them as mere financial support rather than a vital contribution in the design process. As such, the purpose of this research can nurture the following advantages;

a. By understanding how these two groups perceive space during the process of making, better communication skills can be achieved between the client and architect during the design development stage.

b. By understanding the norms regarding the methods of how specialists and non-specialists shape their spaces, we can improve architectural education, perhaps also improving clarity throughout the design process.

c. The prospect of such experiments can help to develop a prototyped creativity test in the future for students or professionals to test or improve their creativity rate (similar to testing knowledge in IQ tests).

\section{Research Objective}

The research attempted to understand the relational differences between both groups' approach methods in space making experiments. This is carried out by observing the process of model making using Lego blocks of 1:10 scale. The next exact repeated model making experiments will be conducted without the subjects' prior knowledge. This is performed so that effective use of the 'micro slip' method can be used to calculate the differences, by analyzing the micro act patterns in their approaches.

Edward Reed termed the 'Micro-slip' method in order to explain how our first hand experiences are becoming artificial due to the diluted second hand experiences we have been experiencing. According to his theory, our current acts are indirectly derived from our past experiences. We will look at the subjects' interactions with the Lego experiment in terms of their 'approach in developing space element', their 'methodology consistency', their 'memory in making space', 'concept of scale' as well as the kind of 'questions asked'. (Tables 2. and 5.) By highlighting general key patterns in how we make spaces, we can make conclusions to improve communications between specialists and non-specialists, whilst attempting to understand some aspects of creativity skills. More importantly, the results can also identify basic patterns used as a theoretical model to understand how we actually 'approach' to make space.

\section{Research Method}

The subjects are invited to create an enclosure using less than 100 Lego blocks within 15 minutes under a specific brief. (Refer to Table 1.) Each Lego block has a 1:2:1 proportion, which allows for extensive possibilities to create different sorts of volumes and layouts. This brief was designed to study and differentiate whether the subjects prioritized either form-making without any concern for the feasibility of construction or vice versa. (Refer to Table 6.)

The model making experiments was divided into

Table 1. Brief of Lego Making Experiments

\begin{tabular}{|c|c|}
\hline No & Task Requirements \\
\hline 1 & $\begin{array}{c}\text { An enclosure to relax in where others can also enter } \\
\text { The model created from the Lego blocks will } \\
\text { eventually be built into 1 to 1 scale using cardboard } \\
\text { boxes with the same proportions. }\end{array}$ \\
3 & $\begin{array}{c}\text { Therefore it is strongly encouraged to think about the } \\
\text { possibility of 1 to 1 scale construction } \\
4\end{array}$ \\
5 & $\begin{array}{c}\text { Decide the roof yourself as long as the physics in } \\
\text { reality can allow. } \\
6\end{array}$ \\
& Originality and skill is appreciated \\
When not sure, questions are welcome.
\end{tabular}


the following 2 parts. Firstly, the students were strictly told to understand a fixed brief (Table 1.) before conducting the Lego block experiments. The subjects were encouraged to ask any questions during the experiments, which will be video recorded and analyzed accordingly. The quality of the questions asked during the experiments will both be used as a method of comparison and to form part of the conclusions later. (refer to Table 5.)

When they have finished their required task, they will be asked to replicate the exact same models which they had previously made using a separate identical set of Lego blocks. The subjects will be told to precisely repeat the same model made during the first trial, without seeing the original design. This is so that the original and the latter 'micro sequences' can be compared and to draw conclusions from their construction process using micro acts patterns; construction (attach act), deconstruction (detach act) and deciding (pause act).

Table 2. Traits to be Observed in the Experiment

\begin{tabular}{|c|c|}
\hline Traits & Description \\
\hline 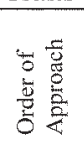 & $\begin{array}{l}\text { Which architectural elements (area, wall, window, } \\
\text { entrance, furniture etc) did they put priority on? } \\
\text { Was there a specific preference to approach } \\
\text { certain elements during the experiments? }\end{array}$ \\
\hline 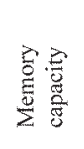 & $\begin{array}{l}\text { How much can the subjects remember after } \\
\text { making? What were the differences in approach } \\
\text { between subjects who could remember and those } \\
\text { who could not? }\end{array}$ \\
\hline 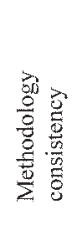 & $\begin{array}{l}\text { During the making process, the subjects' } \\
\text { model-making action can be rationalized into } \\
\text { three primary micro actions (attach, detach and } \\
\text { pause acts). From this perspective, one can use } \\
\text { micro slip to find deviations, trends or patterns } \\
\text { during the process of making space. }\end{array}$ \\
\hline 5 & Did the subjects really understand the concept of \\
\hline 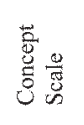 & $\begin{array}{c}\text { scale as they were making models or were they } \\
\text { concerned with mere shapes or forms using } \\
\text { imaginary scale? }\end{array}$ \\
\hline 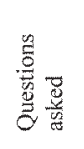 & $\begin{array}{l}\text { As the brief was designed to be minimal, we can } \\
\text { also understand the questions asked by the } \\
\text { subjects (regarding constraints, possibilities of the } \\
\text { construction method or location conditions) }\end{array}$ \\
\hline 竧 & $\begin{array}{l}\text { How did the more creative subjects approach } \\
\text { model making? What were the differences } \\
\text { between creative and less creative subjects in } \\
\text { terms of their behaviors and actions? }\end{array}$ \\
\hline
\end{tabular}

\section{Participants}

Subjects from the university are chosen to engage in experiments. They will be divided into two groups, one with architectural background and the other without architectural background. Subjects from the architectural background are taken from 3rd, 4th year architecture students, masters and doctoral students from the Department of Architecture in Hokkaido University.

Students without architectural background from faculties other than architecture department, represent the non-specialists group. The experiments are conducted from 6 of May 2005 to 17 of August 2005 in room D203 of the Engineering faculty in Hokkaido University. (Table 3.) Two participants from each of the groups displaying interesting characteristics will be selected for analysis. (Figs.4. to 7.)

Table 3. Details of Participants from Hokkaido University

\begin{tabular}{|c|c|c|c|c|c|c|c|}
\hline \multicolumn{6}{|c|}{ Specialists from the Architecture faculty. } & \multicolumn{2}{|c|}{$5 / 6-8 / 17$} \\
\hline & Level & Gender & Other Countries & & $\begin{array}{l}\text { Time } \\
\text { start }\end{array}$ & $\begin{array}{l}\text { Time } \\
\text { finish }\end{array}$ & Date \\
\hline Sol & D2 & $\mathrm{M}$ & Thailand & & $15: 11$ & $15: 52$ & $5 / 13$ \\
\hline $\mathrm{SO} 2$ & D2 & $\mathrm{M}$ & & Japan & $10: 07$ & $10: 45$ & $8 / 14$ \\
\hline S03 & $\mathrm{D} 2$ & $\mathrm{M}$ & Indonesia & & 13:04 & $13: 51$ & $6 / 16$ \\
\hline S04 & D2 & $\mathrm{M}$ & Palestine & & $16: 31$ & $17: 10$ & $6 / 16$ \\
\hline Sos & D2 & $\mathrm{M}$ & Vietnam & & $10: 12$ & $10: 51$ & $5 / 14$ \\
\hline 506 & Di & $M$ & Indonesia & & $13: 26$ & $13: 58$ & $7 / 27$ \\
\hline 507 & D1 & $\mathrm{M}$ & & Japan & $11: 03$ & $11: 32$ & $8 / 16$ \\
\hline 508 & DI & $\overline{1}$ & China & & $20: 16$ & $20: 41$ & $6 / 12$ \\
\hline 809 & $\mathrm{M} 2$ & $M$ & & Japan & $16: 38$ & $17: 06$ & $6 / 2$ \\
\hline$\$ 10$ & $\mathrm{M} 2$ & $\mathrm{M}$ & & Japan & $20: 08$ & $20: 52$ & $6 / 15$ \\
\hline S11 & $\mathrm{M} 2$ & $M$ & & Japan & $16: 49$ & $17: 25$ & $6 / 6$ \\
\hline 512 & M2 & 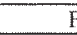 & Columbia & & $14: 19$ & $15: 03$ & $6 / 16$ \\
\hline $\mathrm{S13}$ & M2 & $\mathrm{M}$ & Nigeria & & $16: 23$ & $17: 14$ & $8 / 6$ \\
\hline S14 & $\mathrm{M} 2$ & $\mathrm{~F}$ & Malaysia & & $10: 22$ & 10.59 & $6 / 17$ \\
\hline $\mathrm{S15}$ & M1 & $\mathrm{M}$ & NewZealand & & $10: 18$ & 10.55 & $5 / 22$ \\
\hline 516 & M1 & $\mathrm{M}$ & & Japan & $16: 49$ & $17: 24$ & $6 / 3$ \\
\hline $\mathrm{S17}$ & M1 & 1 & & Japan & $15: 14$ & $15: 57$ & $6 / 4$ \\
\hline S18 & M1 & 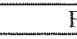 & & Japan & $17: 02$ & $17: 34$ & $5 / 6$ \\
\hline S19 & $\mathrm{Ml}$ & $\bar{E}$ & Malaysia & & $14: 00$ & $14: 53$ & $7 / 7$ \\
\hline S20 & B4 & $M$ & China & & $11: 08$ & $11: 37$ & $6 / 8$ \\
\hline 521 & B4 & $\mathrm{M}$ & & Japan & $10: 24$ & $10: 50$ & $5 / 12$ \\
\hline $\mathrm{S} 22$ & $B 4$ & 1 & & Japan & $16: 11$ & $16: 35$ & $7 / 15$ \\
\hline S23 & 83 & M & & Japan & $10: 21$ & $10: 48$ & $8 / 6$ \\
\hline $\mathbf{S 2 4}$ & B3 & $\mathrm{M}$ & & Japan & $11: 20$ & $12: 45$ & $8 / 17$ \\
\hline \multirow[t]{2}{*}{ S25 } & B3 & $\overline{1}$ & & Japan & $10: 48$ & $11: 17$ & $7 / 1$ \\
\hline & & 17 & 12 & 13 & & & \\
\hline
\end{tabular}

\begin{tabular}{|c|c|c|c|c|c|c|c|c|}
\hline & & & & 25 & & & & \\
\hline \multicolumn{7}{|c|}{ Non-Specialists from other faculties. } & \multicolumn{2}{|c|}{$5 / 13-8 / 17$} \\
\hline No1 & D3 & $\mathrm{M}$ & & Turkey & & $17: 15$ & $17: 45$ & $5 / 17$ \\
\hline No2 & D3 & $\mathrm{M}$ & & & Japan & $10: 14$ & $10: 43$ & $5 / 15$ \\
\hline No3 & D3 & $\bar{M}$ & & & Japan & $09: 55$ & $10: 20$ & $8 / 17$ \\
\hline N04 & $\mathrm{D} 2$ & $\mathrm{M}$ & & Peru & & $10: 05$ & $10: 25$ & $5 / 18$ \\
\hline N05 & D1 & $\mathbf{M}$ & & & Japan & $18: 51$ & $19: 15$ & $7 / 16$ \\
\hline N06 & D1 & M & & Malaysia & & $14: 05$ & $14: 26$ & $7 / 11$ \\
\hline $\mathrm{N} 07$ & DI & $M$ & & & Japan & $11: 02$ & $11: 27$ & $6 / 17$ \\
\hline N08 & D1 & & F & Philippines & & $14: 46$ & $15: 12$ & $6 / 25$ \\
\hline N09 & M2 & $\mathrm{M}$ & & Malaysia & & $15: 01$ & $15: 22$ & $5 / 26$ \\
\hline N10 & M2 & & $\mathrm{F}$ & & Japan & $16: 07$ & $16: 37$ & $7 / 21$ \\
\hline N11 & M2 & $\mathrm{M}$ & & Brazil & & $18: 05$ & $18: 32$ & $6 / 13$ \\
\hline $\mathrm{N} 12$ & $\mathrm{M} 2$ & $\mathrm{M}$ & & China & & $11: 07$ & $11: 27$ & $5 / 14$ \\
\hline N13 & $\mathrm{M} 2$ & $\mathrm{M}$ & & Bulgaria & & $16: 08$ & $16: 26$ & $7 / 5$ \\
\hline $\mathrm{N14}$ & M2 & & $\mathrm{F}$ & England & & $12: 11$ & $12: 36$ & $6 / 3$ \\
\hline N15 & $\mathrm{M} 2$ & & $\mathrm{~F}$ & Argentina & & $15: 10$ & $15: 38$ & $5 / 8$ \\
\hline N16 & M2 & $M$ & & Hungary & & $14: 26$ & $14: 54$ & $7 / 4$ \\
\hline $\mathrm{N17}$ & $\mathrm{M} 2$ & $\mathrm{M}$ & & Brazil & & $19: 13$ & $19: 38$ & $6 / 4$ \\
\hline N18 & M1 & $M$ & & India & & $11: 27$ & $11: 49$ & $6 / 8$ \\
\hline N19 & $\mathrm{Ml}$ & $\mathrm{M}$ & & Indonesia & & $12: 11$ & $12: 38$ & $6 / 9$ \\
\hline $\mathrm{N} 20$ & MI & $\bar{M}$ & & Brazil & & $15: 30$ & $15: 58$ & $7 / 11$ \\
\hline $\mathrm{N} 21$ & M1 & & F & Brazil & & $16: 13$ & $16: 40$ & $5 / 14$ \\
\hline $\mathrm{N} 22$ & MI & $\bar{M}$ & & New Guinea & & $17: 15$ & $17: 50$ & $5 / 13$ \\
\hline $\mathrm{N} 23$ & $B 4$ & & $F$ & & Japan & $16: 07$ & $16: 42$ & $6 / 3$ \\
\hline N24 & $B 4$ & & F & Bulgaria & & $18: 05$ & $18: 37$ & $5 / 14$ \\
\hline \multirow[t]{2}{*}{$\mathrm{N} 25$} & B3 & & $\mathrm{F}$ & & Japan & $11: 07$ & $11: 42$ & $5 / 28$ \\
\hline & & 17 & 8 & 12 & 13 & & & \\
\hline Total & & & & 25 & & & & \\
\hline
\end{tabular}

\begin{tabular}{|c|c|c|c|c|c|c|c|c|}
\hline \multicolumn{7}{|c|}{ \#Subjects not used due to technical failures } & \multicolumn{2}{|c|}{$5 / 10-5 / 16$} \\
\hline U1 & D1 & M & & Nepal & & $9: 03$ & $9: 25$ & $5 / 16$ \\
\hline U12 & DI & & $F$ & & Japan & $18: 05$ & $18: 26$ & $5 / 14$ \\
\hline U3 & M2 & M & & India & & $10: 15$ & $10: 67$ & $5 / 16$ \\
\hline U4 & $\mathrm{M} 2$ & & $F$ & & Japan & $09: 13$ & $09: 46$ & $5 / 15$ \\
\hline $\mathrm{U5}$ & $\mathrm{M} 2$ & M & & Brazil & & $18: 07$ & $18: 47$ & $5 / 12$ \\
\hline $\mathrm{U} 6$ & M2 & & $\bar{F}$ & Indonesia & & $19: 05$ & $19: 26$ & $5 / 14$ \\
\hline U7 & MI & & F & & Japan & 19:04 & $19: 26$ & $5 / 16$ \\
\hline $\mathrm{U} 8$ & M1 & $\mathrm{M}$ & & China & & $21: 40$ & $22: 14$ & $5 / 11$ \\
\hline 19 & B4 & $\mathrm{M}$ & & Brazil & & $21: 02$ & $21: 29$ & $5 / 12$ \\
\hline \multirow[t]{2}{*}{ U10 } & 84 & $M$ & & Bulgaria & & $21: 07$ & $21: 48$ & $5 / 10$ \\
\hline & & 6 & 4 & 7 & 3 & & & \\
\hline Total & & & & & & & & \\
\hline
\end{tabular}




\section{Analyzing Main Micro Acts in Experiments}

In the process of constructing (using Lego blocks), fundamental acts such as attach acts, detach acts and pause acts can be observed. (Fig.1.) Attach acts occur when two Lego blocks or parts are connected, while detach acts occur when two Lego blocks or parts are detached. The pause acts can occur within attach and detach acts as well as before or after the act is completed. (Fig.2.) To make a model, the subjects have to engage in different combinations of these acts. All the movements in the experiment can be summarized in this way, showing different combinations of these acts when the subjects are engaging with the Lego blocks.

We also observed transitional stages in between the main micro acts. For example, in the main attach act, we observed more subtle acts such as 'attach act', 'attaching act' and 'attached act'. (Table 4.)

Table 4. Definition of Micro Constructing Acts

\begin{tabular}{|l|l|}
\hline Act types & Description \\
\hline Attach & $\begin{array}{l}\text { Indicates the instant start of attaching before } \\
\text { continuing into the process of attaching }\end{array}$ \\
\hline Attaching & $\begin{array}{l}\text { Indicates the process in between the beginning of } \\
\text { attaching and complete finished act of attaching }\end{array}$ \\
\hline Attached & $\begin{array}{l}\text { Attached act indicates when two Lego pieces are } \\
\text { completely connected together. }\end{array}$ \\
\hline Detach & $\begin{array}{l}\text { Indicates the instant start of detaching before } \\
\text { continuing into the process of detaching. }\end{array}$ \\
\hline Detaching & $\begin{array}{l}\text { Indicates the process in between the beginning of } \\
\text { 'detach act' and the finished act of detach act. }\end{array}$ \\
\hline Detached & $\begin{array}{l}\text { Detached act indicates the finished act of two Lego } \\
\text { pieces being completely connected together. }\end{array}$ \\
\hline Pause & $\begin{array}{l}\text { When the subjects are not engaging in any of the } \\
\text { above acts. (usually indicated when their hands are } \\
\text { not moving) }\end{array}$ \\
\hline
\end{tabular}

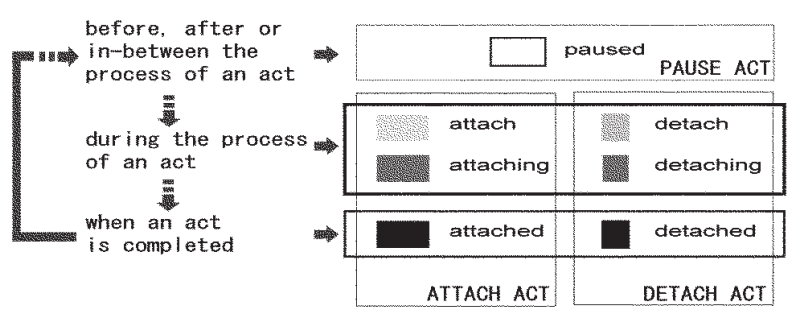

Fig.1. Main Micro Acts in Lego Making Process

We also observed that there are 4 possible main combination types that determined the available choices which one can make during the model making experiment. (Fig.2.)

a. Attach act followed by Attach act

When one completes an attach act and continues to another attach act.

b. Attach act followed by Detach act

One can repeat the attaching acts to a certain level and start to detach, hence the second type, attach act followed by detach act can be highlighted.

c. Detach act followed by Attach act

When one decides to continue, attach acts are performed after detaching acts. d. Detach act followed by Detach act

When one engage in detach acts after another detach act.

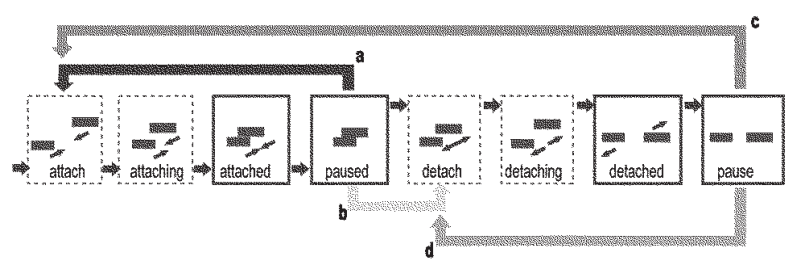

Fig.2. Cycle of Constructing Micro Acts

When the above Micro act cycles are sequentially ordered accordingly, the individuals' approach process can be read like a time chart; 'micro sequence'. (Refer to Figs.4. to 7.) The amount of speed and articulation during the process of connecting Lego blocks into recognizable architectural elements can be used to identify different possible approaches by reading the amount and frequency of pauses in micro act patterns.

\section{Analyzing Pattern Types and Traits in the Micro Act Process}

During the Lego experiment processes, different combinations of possible main micro acts patterns are observed. Three distinct combination patterns, such as continuous, discontinuous and prolonged pause patterns, ranging from low to high frequencies are noticed. (Fig.3.)

- Continuous patterns combination

The subjects usually begin the experiment using a sequence of attach acts. When they perform such acts in a continual manner with little pauses, it indicated that they have some notion of what they are making. Continuous patterns can also occur in detach acts when one decides to detach a large part of the Lego blocks to reuse the pieces in a different manner.

- Discontinuous patterns combination

This is another possible pattern which subjects undergo during construction, taking irregular short or long pauses before beginning to perform the next act. These excessive 'disrupted pauses' suggest that subjects are approaching the making process in either an 'indecisive' or 'trial and error' manner. If they are decisive, they should repeat the same experiment in a more fluent manner. It is when comparing the micro sequences between initial and repeat trials that we can conclude whether the subjects are decisive or merely indecisive during their first attempt.

- Prolonged pause combination

The third pattern is seen when one cannot even start to pick up the Lego pieces to commence construction, indicating either the process of deep considerations or difficulties in forming strategies essential to satisfy the brief.

Two participants from each category with different important characteristics are selected, where their micro slip patterns sequence in the experiments are mapped accordingly. (Refer to Figs.4. to 7.) 

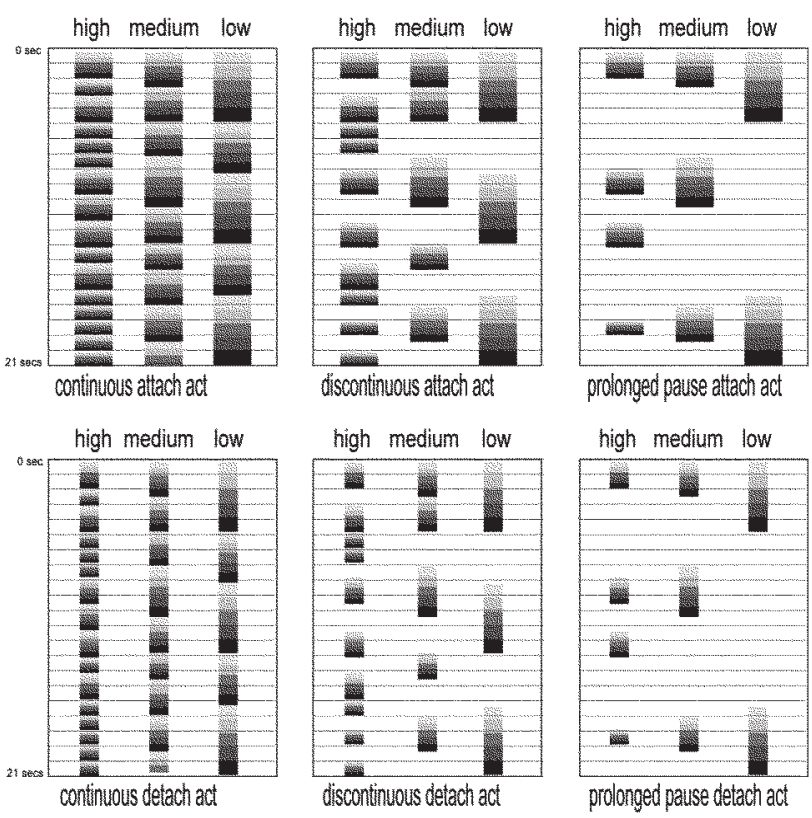

Fig.3. Key Micro Acts Patterns Combinations

Bernstein (1996) wrote about how the body (e.g. the central nervous system) has learnt to control movement. In his search on the understanding of how anyone can improve his or her learning of motor skills, his fundamental conclusion was that movement is not controlled by one executive center but by a hierarchy of patterns of control.

In this research, we understood that the specialists are more experienced in understanding space as well as solving spatial problems. As such, theoretically they should achieve more advanced results, and display more developed and articulated patterns than the nonspecialists. By comparing the combination of micro acts, micro act cycles and micro act patterns during the construction of the Lego models, we can perhaps highlight essential key approach methods in the process of creating space.

These patterns are developed incrementally, either from experiences accumulated previously or during their current interaction with the Lego blocks. Although subjects do not often repeat their exact patterns at the same position or time, we can see that they share some similarities in traits when looking at the overall micro sequence. (Figs.4. to 7.) These patterns are evident when they are in the attaching rather than detaching processes. It is also interesting to note that in the repeated experiments, most of the nonspecialists do not take the time to correctly match what they had constructed previously.

Table 5. Difference in Traits between Specialists and Non Specialists

\begin{tabular}{|c|c|}
\hline & Non Specialists \\
\hline Definition & $\begin{array}{l}\text { Ones who did not undergo or engage in any } \\
\text { architectural education or work }\end{array}$ \\
\hline $\begin{array}{l}\text { Order of } \\
\text { Approach }\end{array}$ & $\begin{array}{l}\text { Subjects who spent a longer time to make space } \\
\text { seemed to either have difficulties to create forms or }\end{array}$ \\
\hline & $\begin{array}{l}\text { express their ideas according to the required brief. } \\
\text { In contrast, some subjects displayed little } \\
\text { difficulties and took less time to finish replicating } \\
\text { the models. }\end{array}$ \\
\hline $\begin{array}{l}\text { Methodology } \\
\text { consistency }\end{array}$ & $\begin{array}{l}\text { When they were making spaces, they rely on the } \\
\text { 'see, think and make' relationship involved in a } \\
\text { trial and error way of realizing space. Their } \\
\text { approach was similar in both the first and repeated } \\
\text { experiment suggesting that they were more in the }\end{array}$ \\
\hline
\end{tabular}

Memory

capacity

Concept of scale

Questions asked

Specialists

Ones who undergo or engage in the field of architectural education or work for a period of 3 years or more.

Using a greater variety of micro patterns to construct models yet only produced a variety of box-like enclosures. They dealt in different parts as well as the whole. When they are interacting with the building blocks, their process patterns are more inconsistent in both the first and repeated experiments.

In the first trial, the 'more careful' subjects tended to make spaces with more pattern deviations, showing more complex micro acts but yet produced similar boxed forms with similar wall patterns. The 'less careful' subjects showed some form of difficulties, taking a longer time to reconstruct what they had made during the first attempt.

They remembered the volumes of the space more accurately even though they took a longer time to finish because they realized their mistakes during the experiments, hence spending more time to correct them. Even though some spent less time to finish, the overall average time taken by the specialists is eventually more than the non-specialists.

Scale is a very difficult concept to grasp, even for most subjects who have an architectural background. The ones who tended to have fewer scale deviations were the ones who understood the specific dimension of the models. Those who made an artificial human model before or during the experiments performed better in scale accuracy values than those who didn't.

Subjects with an architectural background tended to ask more practical questions regarding the possibilities and constraints about building techniques or about site conditions. They displayed more technical skills in manipulating structure, light and entry closer to the realm of $1: 1$ scale, in reality. 


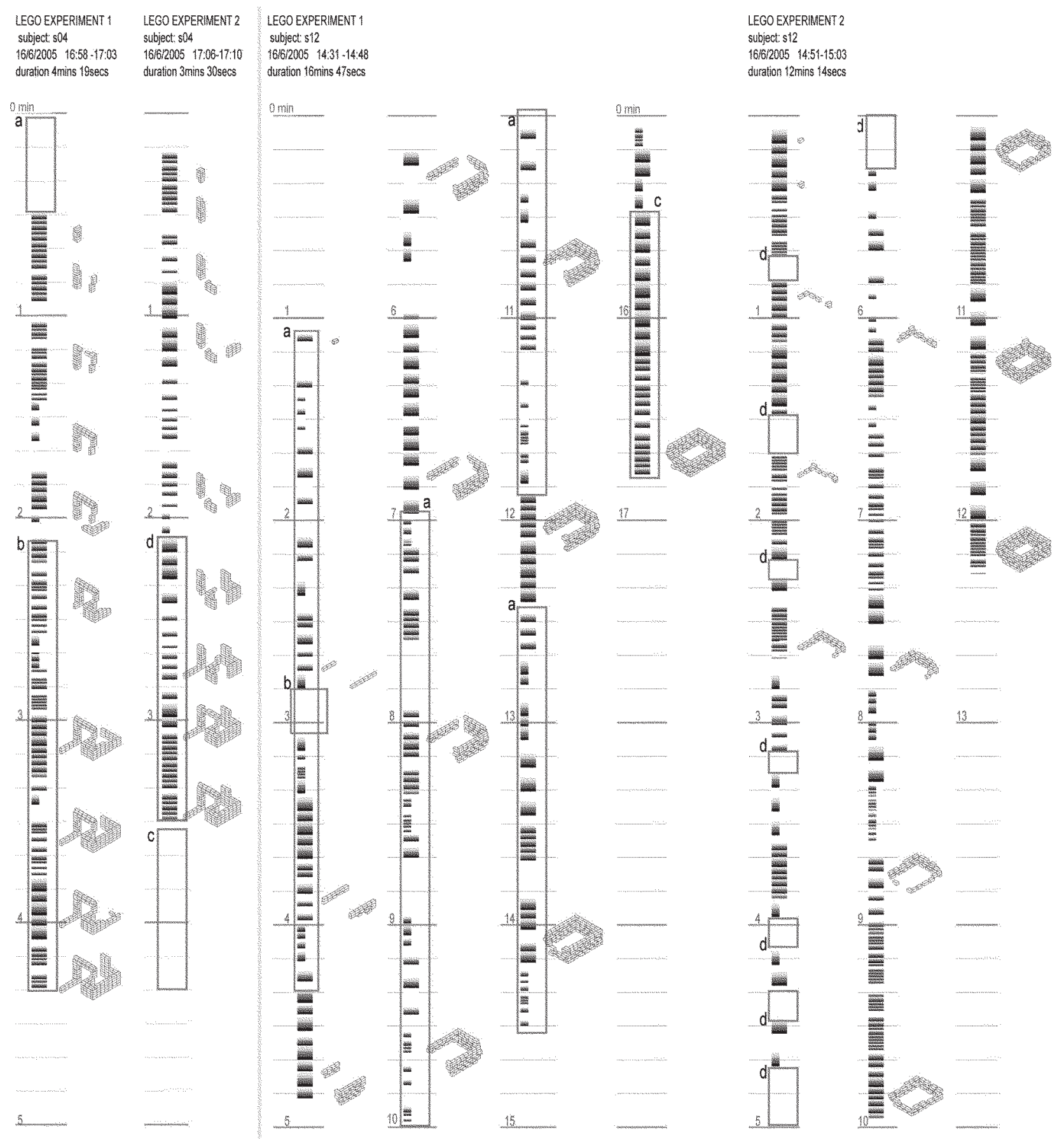

Fig.4. Micro Slip of Specialist s04's Fig.5. Micro Slip of Specialist s12's Micro Acts Process (Type S-a)

Micro Acts Process (Type S-b)

a. Using relative short time ( 30 seconds) before beginning to construct without testing the properties of the Lego blocks. This suggests that he already knew what to make from the beginning.

b. Using very little time to decide what to make, continuously attaching the shapes showing some micro act patterns similar to subject $n 21$.

c. In his second attempt, repetifive series of pauses were made as he attached. He finished in lesser time than previous attempt. d. Toward the end of the model, he finished quickly in continuous attach acts. notes: Specialist s04's model is most unique among the participants sharing many creative attributes.

a. The subject discontinuously attaches and detaches the Lego blocks slowly in various pattems throughout the experinent. b. Pausing regularly in discontinuous attach and detach act pattems, indicating the process of careful considerations. c. Towards the end, continuous attach patterns are observed

d. In her second attempt, the subject reconstructed the model with fewer pauses, indicating that she had little difficuly in repeating the models. This suggests that the amount of pauses made in the first attempt contributes to the accuracy of the second model.

Overall characteristics Type S*b : Engaging in inconsistent mixture of regular attaching patterns together with discontinuous attach and detach patterns during their first attempt in the experiment. This suggests that the subjects had not formalized their ideas, engaging in the search for potentials during the process. In the second attempt, the majority of them engaged in high continuous attach patterns (indicating confidence) but realized at the middle of the process that they had made some errors (engaging in detaching acts) and eventually taking longer time to finish.

Overall characteristics Type S-a: We observed that most of them either took extreme pauses in the beginning but continued at a higher rate of speed and frequency with little detach acts showing more continuous attach patterns, suggesting that they had already formalized the idea in the brain before approaching the brief. (perhaps obtained from their previous experiences) 


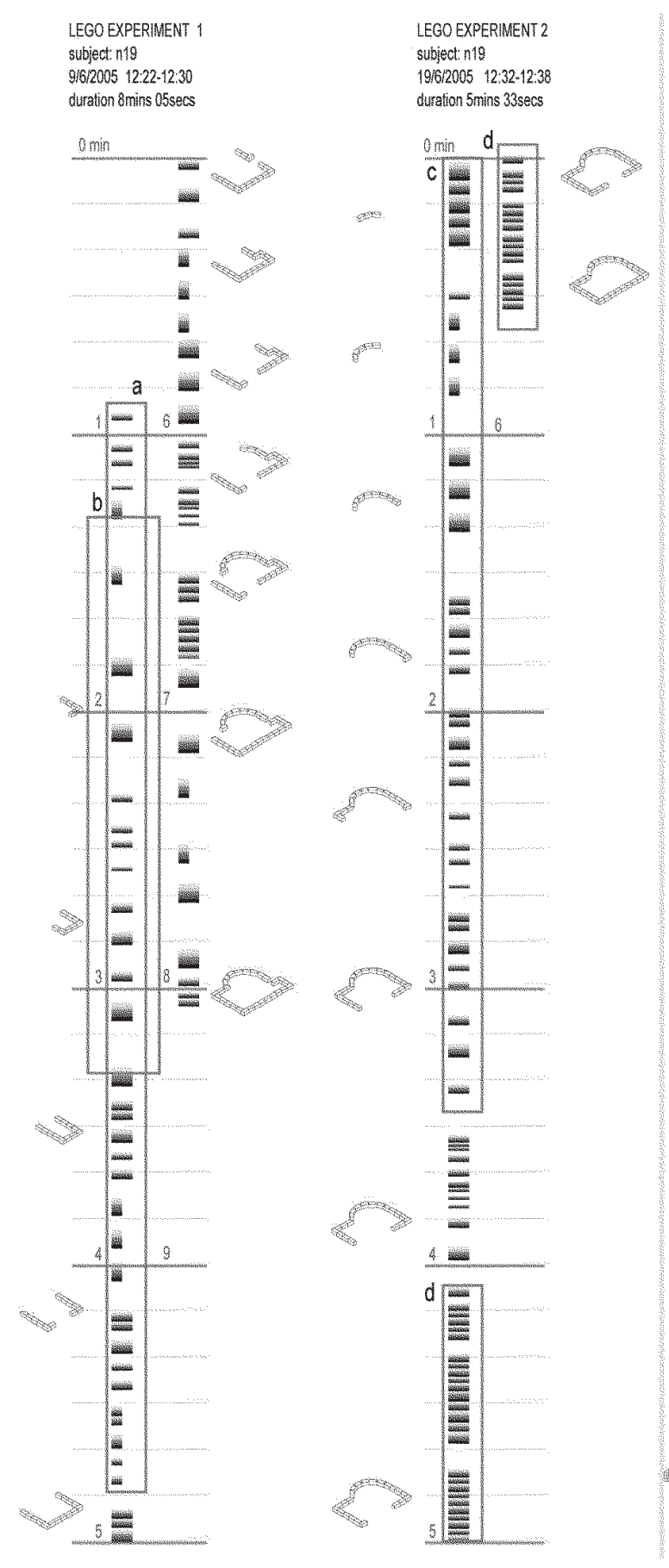

Fig.6. Micro Slip of Non-specialist n09's Micro Acts Process (Type NS-a)

a. The subject made indecisive movements showing low levels of discontinuous attach and prolonged pause patterns throughout the process. b. Slow discontintous attach and detach act patterns indicate that the subject seemed to have some difficulties in making the space. Although he finished faster than other subjects, he did not satisfy the requirements stated in the brief.

c. In the second attempt, he attached continuousiy in the beginning but continued with a series of prolonged pause pattems and discontinuous acts. d. Towards the end, he attached quickly, nevertheless larger deviations compared to his previous model were made.

Overall characteristics Type NS-a; Engaging the attaching and defaching process in a very slow manner, finally resulting in a very abstract results. In the second attempt, they usually manage to follow the same manner due to the simplicity of the original model made in the first attempt.

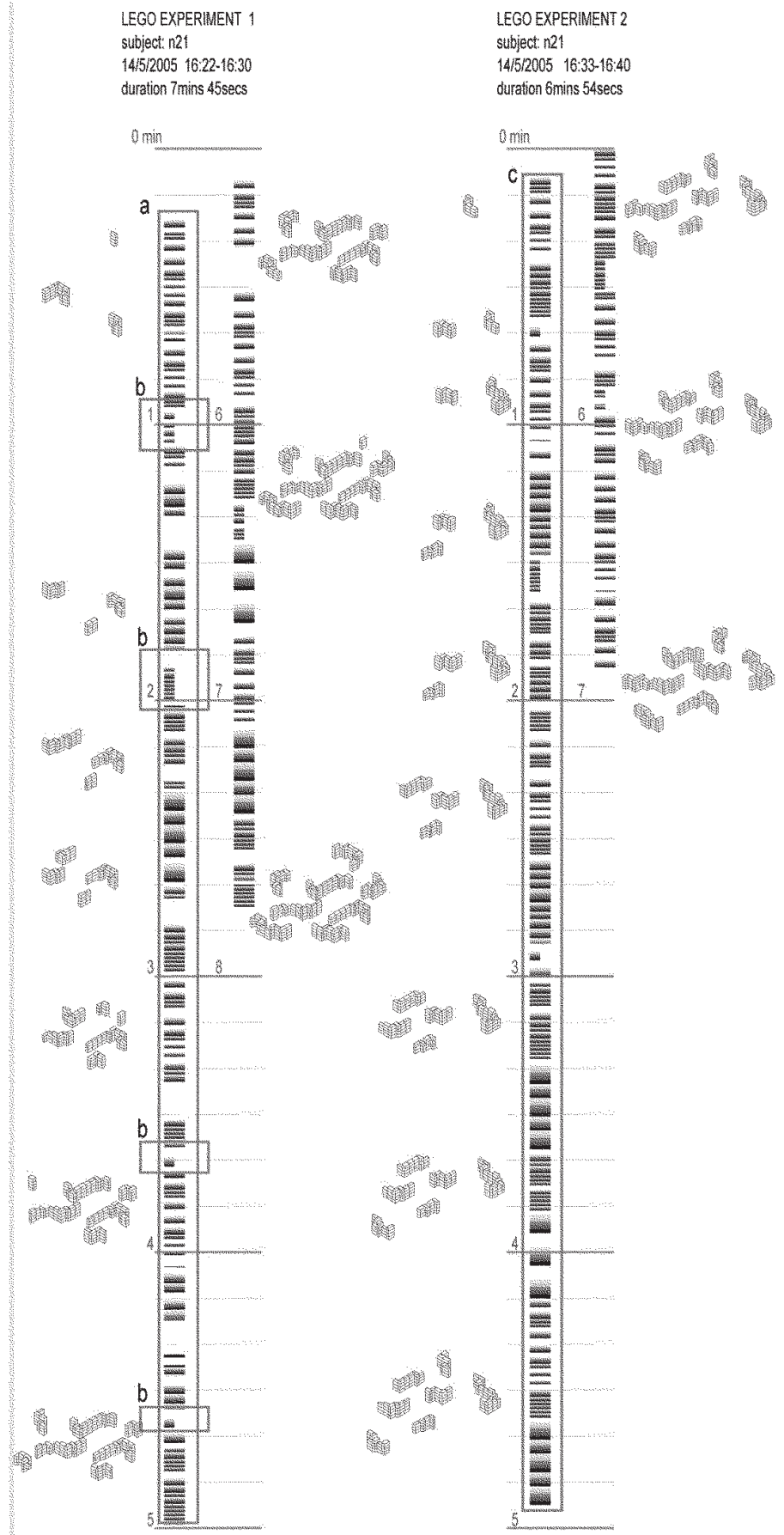

Fig.7. Micro Slip for Non-specialist n21's Micro Act Process (Type NS-b)

a. Begin to construct relatively quickly, showing a series of long continuous attach act pattems with regular pauses in between.

b. Relative minimal detaching acts are observed, which suggests that this subject is playing rather than consfructing.

c. In the second experiment, we can see similar continuous attach act pattems in terms of the. pause frequency made previously. This suggests that he shows no difficulties in remembering

his previous acts although we can see that there are some deviations in model form when compared to the one made from the first experiment.

notes: Similar patterns between the first and the second suggest that his movements are automated rather than conscious.

Overall characteristics Type NS-b: Those who showed more prolonged pause patterns were perhaps unsure about their moves because they are deprived of technical skills to understand and construct even a simple enclosure space. While those who show more continuous attach patterns see Lego as a source of fun in making, suggesting that they are playing rather than constructing. 
Table 6. Empirical Values of Micro Acts Sequence

\begin{tabular}{|c|c|c|c|c|c|c|c|}
\hline \multirow{2}{*}{\multicolumn{2}{|c|}{ Subjects }} & \multirow[b]{2}{*}{$\mathrm{TD}$} & \multicolumn{3}{|c|}{ Technical aspects } & \multicolumn{2}{|c|}{ Approach } \\
\hline & & & LS & $\mathrm{NM}$ & $\mathrm{SA}$ & $\mathrm{CV}$ & $\mathrm{PT}$ \\
\hline \multirow{8}{*}{ है } & sot & -0.13 & 5 & 2 & 3 & 2 & 0.02 \\
\hline & 504 & -0.28 & 4 & 4 & 2 & 1 & 0.09 \\
\hline & S07 & +0.09 & 4 & 3 & 2 & 2 & 0.07 \\
\hline & $\$ 08$ & -0.18 & 3 & 4 & 2 & 1 & 0.14 \\
\hline & $\$ 11$ & -0.15 & 4 & 5 & 2 & 2 & 0.12 \\
\hline & $\$ 13$ & -0.11 & 3 & 2 & 4 & 2 & 0.13 \\
\hline & $\mathrm{S} 16$ & +0.09 & 4 & 1 & 3 & 3 & 0.07 \\
\hline & $\$ 21$ & -0.23 & 2 & 5 & 4 & 1 & 0.11 \\
\hline & rage & -0.11 & 3.63 & 3.25 & 2.75 & 1.75 & 0.09 \\
\hline \multirow{17}{*}{ 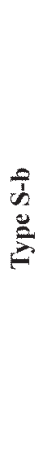 } & $\mathrm{S} 02$ & -0.14 & 5 & 3 & 5 & 4 & 0.14 \\
\hline & S03 & -0.12 & 4 & 3 & 2 & 5 & 0.23 \\
\hline & S05 & +0.07 & 5 & 2 & 4 & 4 & 0.14 \\
\hline & S06 & -0.11 & 5 & 4 & 2 & 3 & 0.31 \\
\hline & $\$ 09$ & +0.16 & 4 & 3 & 4 & 4 & 0.44 \\
\hline & $\$ 10$ & +0.17 & 3 & 6 & 1 & 3 & 0.43 \\
\hline & $\$ 12$ & -0.14 & 4 & 2 & 2 & 4 & 0.24 \\
\hline & S14 & -0.22 & 5 & 4 & 4 & 4 & 0.18 \\
\hline & $\$ 15$ & +0.09 & 4 & 3 & 3 & 5 & 0.13 \\
\hline & S17 & -0.31 & 5 & 4 & 4 & 4 & 0.16 \\
\hline & $\$ 18$ & +0.03 & 3 & 4 & 4 & 5 & 0.22 \\
\hline & \$19 & -0.12 & 5 & 6 & 3 & 3 & 0.14 \\
\hline & $\$ 20$ & +0.26 & 5 & 8 & 5 & 4 & 0.28 \\
\hline & $\$ 22$ & -0.21 & 4 & 4 & 4 & 5 & 0.35 \\
\hline & $\$ 23$ & +0.19 & 5 & 3 & 5 & 3 & 0.19 \\
\hline & $\$ 24$ & -0.28 & 3 & 3 & 4 & 5 & 0.29 \\
\hline & $\$ 25$ & -0.16 & 5 & 1. & 5 & 4 & 0.12 \\
\hline \multicolumn{2}{|c|}{ Average } & -0.05 & 4.35 & 3.71 & 3.19 & 4.06 & 0.23 \\
\hline \multicolumn{2}{|c|}{$\begin{array}{c}\text { Total } \\
\text { Average }\end{array}$} & -0.08 & 3.99 & 3.48 & 3.17 & 2.90 & 0.16 \\
\hline \multirow{14}{*}{$\begin{array}{l}\sum_{0}^{J} \\
z\end{array}$} & Not & -0.34 & 3 & 2 & 1 & 3 & 0.33 \\
\hline & $\mathrm{N} 03$ & +0.12 & 5 & 3 & 1 & 3 & 0.24 \\
\hline & $\mathrm{N} 04$ & -0.56 & 3 & 3 & 2 & 3 & 0.26 \\
\hline & No7 & -0.23 & 4 & 3 & 1 & 2 & 0.13 \\
\hline & No9 & -0.46 & 4 & 2 & 2 & 3 & 0.38 \\
\hline & $\mathrm{N} 12$ & -0.32 & 3 & 4 & 3 & 3 & 0.12 \\
\hline & $\mathrm{N} 15$ & +0.24 & 2 & 8 & 1 & 4 & 0.36 \\
\hline & N16 & -0.30 & 2 & 3 & 2 & 3 & 0.18 \\
\hline & N18 & +0.22 & 5 & 2 & 4 & 2 & 0.33 \\
\hline & N19 & -0.34 & 3 & 3 & 1 & 3 & 0.27 \\
\hline & $\mathrm{N} 20$ & -0.15 & 3 & 2 & 2 & 4 & 0.41 \\
\hline & $\mathrm{N} 22$ & +0.28 & 5 & 4 & 2 & 3 & 0.25 \\
\hline & $\mathrm{N} 23$ & -0.14 & 3 & 3 & 1 & 2 & 0.23 \\
\hline & $\mathrm{N}_{2} 25$ & +0.12 & 5 & 2 & 2 & 2 & 0.11 \\
\hline & rage & -0.13 & 3.57 & 3.14 & 1.79 & 2.86 & 0.26 \\
\hline \multirow{11}{*}{ 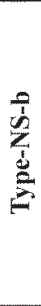 } & $\mathrm{N} 02$ & 0.12 & 3 & 4 & 3 & 2 & 0.03 \\
\hline & N05 & -0.22 & 2 & 3 & 2 & 1 & 0.13 \\
\hline & N06 & 0.12 & 1 & 2 & 2 & 3 & 0.15 \\
\hline & N08 & 0.14 & 2 & 4 & 1 & 1 & 0.04 \\
\hline & $\mathrm{N} 10$ & -0.15 & 3 & 1 & 3 & 2 & 0.01 \\
\hline & Nl1 & -0.31 & 4 & 7 & 3 & 1 & 0.13 \\
\hline & $\mathrm{N} 13$ & 0.16 & 2 & 2 & 1 & 2 & 0.07 \\
\hline & $\mathrm{N} 14$ & -0.18 & 2 & 1 & 1 & 1 & 0.11 \\
\hline & N17 & 0.04 & 1 & 4 & 1 & 2 & 0.13 \\
\hline & $\mathrm{N} 21$ & -0.14 & 4 & 1 & 1 & 1 & 0.09 \\
\hline & N24 & -0.11 & 3 & 2 & 3 & 2 & 0.18 \\
\hline \multicolumn{2}{|c|}{ Average } & -0.07 & 2.45 & 2.81 & 1.91 & 1.64 & 0.1 \\
\hline \multicolumn{2}{|c|}{$\begin{array}{c}\text { Total } \\
\text { Average }\end{array}$} & -0.1 & 3.01 & 2.98 & 1.85 & 2.25 & 0.13 \\
\hline
\end{tabular}

\# The definition of head titles in Table 6 is explained below.

Time difference (TD): percentage difference between the amount of time taken to complete the first experiment, divided by the time taken to complete in the second experiment where +ve values indicates time taken in repeated experiment exceeding the first, while-ve values is vice versa.

Level of Similarities (LS): the amount of similarities between the model made in the first and repeated experiment. Considering the accuracy in volume of model space, design details in plan and section, ranging from 1 to 5 , where 5 indicates little or no deviations with the original model made; indication of excellent memory capacity.

Level of mistakes (NM): indicates the number of connections made not according to the realistic feasibility and specification of 1:1 scale construction. Instead relying on the Lego's attaching properties to achieve their desired forms.

Scale accuracy $(\boldsymbol{S A})$ : indicates the amount of difference in the intended scale and the actual scale made by the subjects, ranging from 1 to 5 where 5 is where the model at 1:10 scale is made according to the scale specification required in 1:1 scale.

Complexity in pattern variations (CV): indicates the amount of complexity in deviations between patterns sequences from the first experiments with repeated experiments, ranging from 1 to 5 , where 5 indicates most complexity in deviations.

Pauses in first and repeated attempt (PT): the percentage of time spent 'pausing' during the act of making. Low percentage values indicates that their acts are automated towards using the subconscious while higher values can either indicate thinking consciously or difficulties in thinking. (Bernstein 1996)

\section{Conclusion}

By comparing the approach of the subjects using micro acts, we realized that all the subjects displayed different combinations of micro act patterns in both first and repeated experiments. From an overall point of view, we can categorize them into 4 different types of approach patterns, S-a and S-b, NS-a, NS-b. (Figs.4. to 7.) These key types also considered the subtle difference in micro acts variations in both first as well as repeated experiments.

The specialists in type $S$ - $b$ showed higher deviation values of the overall micro act combination patterns in both experiments $(\mathrm{CV}=4.06)$ when compared to the non-specialists in type $N S-b(\mathrm{CV}-=1.64)$. This indicates that they engaged the experiment with a greater variety of pattern frequencies than the non-specialists. The explanation for such higher values could be that they were consciously considering the brief's technical and creative requirements rather than being concerned with the realm of play.

In this experiment, although the overall specialists took more time $(\mathrm{TD}=-0.08)$ to repeat the original models than non-specialists ( $\mathrm{TD}=-0.1)$, but they achieved a higher level of similarities $(\mathrm{LS}=4.35)$ and higher scale accuracy $(\mathrm{SA}=3.17)$, suggesting that they were likely to be considering the possible feasibilities of realizing in $1: 1$ scale more than the non-specialists.

Some of the non-specialists such as (N03, N07, N09, $\mathrm{N} 11, \mathrm{~N} 18, \mathrm{~N} 21, \mathrm{~N} 22, \mathrm{~N} 25)$ reproduced more accurate models and in a sense they out-performed the specialists such as (S08, S10, S13, S18, S21, S24) in memory capacity (indicated by the values of LS), which prompts the question of the appropriateness of today's architectural education.

\section{References}

1) Gibson, E.J., and Pick, A.D. (2000). An Ecological Approach to Perceptual Learning and Development. Oxford University Press.

2) Gibson, J.J. (1986). The ecological approach to visual perception. Lawrence Erlbaum Associates.

3) Reed, E.S. (2001). James J. Gibson and the Psychology of Perception. Yale University Press.

4) Reed, E.S. (1996). Encountering the World, Towards an Ecological Psychology. Oxford University Press.

5) Bernstein, N.A. (1996). Dexterity and Its Development. Lawrence Erlbaum Associates.

6) Hawkins, J. (2004). On Intelligence. Times books. 